\title{
The Job that Fits
}

\section{Andrew Hague* \\ CellSonic: Manufacturers of Medical Equipment, United Kingdom}

*Corresponding author: Andrew Hague, President, CellSonic: Manufacturers of Medical Equipment, United Kingdom, Tel: +1 315210 6307; Email: cellsonic.beauty@gmail.com

\section{Clinical Note \\ Volume 2 Issue 4}

Received Date: June 05, 2018

Published Date: July 09, 2018

DOI: $10.23880 /$ eoij-16000164

\section{Abstract}

Getting the right people into the right job is essential for prosperity and peace. The job or role has to fit each person who all have differing abilities according to their mentality. Brains are not all the same. Identifying the type of person is part of ergonomics. Changing the person is difficult and disturbing. It is the job that has to be adjusted. What that may involve is the subject of this essay.

Keywords: Shifts; Strain; Mentalities; Education; Imaginations; Exams; Position

\section{Clinical Note}

Ergonomics has its origins in Time and Motion Studies which aimed to increase output from manual workers in factories. A supervisor armed with a stop watch would observe the repetitious movements of the worker and suggest that by placing a basket nearer or a handle at a more convenient height a fraction of a second could be lopped off the work cycle which then amounts to more items made during the shift. The benefit was said to be making the job easier with less strain.

Since then, the emphasis on fitting the surroundings to the person has become the definition of ergonomics with the classic example being the design of the driving position in a motor car that has to accommodate people of different sizes. With slides, many adjustments are possible.

\section{Mentality}

Ergonomics then expanded the definition to study a person in a working environment. The emphasis was on compatibility with the body, literally fitting the person to the work station. A more important consideration was often ignored and this I shall call the person's mentality. In medicine, the relationship between mind and body is only now being understood in the west although eastern, so called mystical societies, have appreciated its importance for thousands of years.

A person's mentality is the way the person thinks. That you are reading this paper suggests that, like me, you have had an upbringing and education which has not helped you to understand people. You probably did well at school, passed exams, went to university and got a managerial job. That means you have been isolated and worse than that you think you know a lot about the world.

Forty years ago, I owned a factory making bicycle components. One of the items, top eyes, had to be linished on a sanding belt to remove the rough marks left by a saw cut. It took from 5 to 10 seconds to press each top eye onto the linishing belt and there were thousands of top eyes to process. A boy about eighteen years old came for a job so I started him on the linisher at eight o'clock in the 


\section{Ergonomics International Journal}

morning. The tea break was at eleven o'clock and from what I could hear in my office of the sound of the linisher, he had not stopped for three hours. It is a repetitively boring job so as he went back to the shop floor after the break I caught up with him and suggested he may like a change and do some drilling. He looked very offended and asked me if he had not done well on the linishing. I said he might like a change and he replied that he thought linishing was his job. I went with him to the machine and could see in the dust on the floor where his feet had been for three hours; he had stood there moving only his arms and hands and was content with what he was doing.

I had made a serious mistake. He was well suited to monotonous work and with the best that education could offer me; I had never met such a person before. He had the right mentality for the job. No amount of writing three-hour exams at university and discussions in tutorials with professors had prepared me for people who can switch off their minds. In the years since, I have come to the conclusion that the young man was typical of a majority and I am in the minority. Humans differ more in their mentality than their physical structure. It is the mentality adjustment that gives ergonomics its greatest challenge.

Another interesting discovery at the bike factory was the problem of a good brain without opportunity. The girl was 16 and wanted a job because she was bored staying at home looking after her baby; that was a job her mother, the grandmother, could do. I let her start in the sewing department with all the other females. The men were on the engineering side. The young girl was too talkative and disruptive. I asked for her school reports and she appeared to have been doing well until she became pregnant and had to leave school. Sales were growing so we needed help in the dispatch department where the orders had to be collated, packed and the parcels addressed. This required some concentration, knowledge of the product range and the ability to write legibly. Fortunately, the girl did all this well and I had fitted her into the right role.

The factory was in a deprived area, so called because the coal mines and steel works had closed and new companies such as mine were persuaded with development grants to move in and create employment. Unfortunately, mining and blast furnaces never offered a wide range of jobs so the better educated youngsters left. It was an intellectual desert that always elected a socialist politician. The people felt exploited. The employer was the enemy and even though the new companies had nothing to do with coal mining the culture in the area passed down from father to son was that loyalty to the trade union was essential for survival.

One day a young man came in looking for a managerial job. From his accent, he was a local. He had been at the school down the road. I asked him what had brought him back to the town. He was surprised.

"How did you know I had left?"

"Because you are bright. You could never stay here so why have you come back?"

He knew I was right. He had come to marry his childhood sweetheart and she wanted to live in the same street as her mother. The young man knew I had touched a sore spot. If he did not fit with the town, did he really fit with the girl he intended to make his wife? I never knew what happened and did not see him again. I was learning. Discover the mentality and then you can place the person.

\section{Hawthorne Studies}

These observations take motivation and productivity further away from the Hawthorne Studies of the 1920s in America. As agriculture became mechanised, labour was released to factories and their muscles and partly their brains were employed to make things. That the interest showed by researchers in the productive efforts of the workers resulted in an increase in output, revealed the drudgery of the work for most of the people. The observing researchers were not thinking of the mentality of the workers. What sort of work were these people best suited to? It was back then a question not worth asking. Did the workers have a choice? If you wanted a better job you needed an education and so few people had that benefit so they were trapped.

\section{Education}

The importance of education is highlighted today in China with the gaokao university entrance exam. Even some American and Canadian universities are recognising gaokao results instead of the internationally recognised Scholastic Aptitude Test (SAT). Gaokao involves rote learning to the exclusion of critical thinking. In 2017, over nine million students took the gaokao exams. Everyone who has progressed through education has taken exams and the preparation for them has been to memorise facts. With an international emphasis on education there is a selection of those with good memories over those whose minds work differently. 


\section{Ergonomics International Journal}

In academia there is a belief that only science is a valid study because it deals with facts; measurable data. If it cannot be measured, it is not fact and thereby subject to manipulation which is only art. This is where I find universities to not be in the real world. They have become a business of publishing research papers whilst industry develops new products. Much of the imagination and innovation in product development has not come from memorising existing facts; it is the result of thinking outside the box, lateral thinking, rebellion, revolution and general deviation from the normal path. Obviously, knowledge is required as a basis on which to build new ideas but minute detail is needed less now that information is stored and retrieved digitally leaving the mind to freewheel with ideas and creativity. Exams cannot measure creativity and originality.

\section{Memory and Imagination}

It is my contention that creativity and copious memory seldom go together. This has not been measured and would be difficult to measure. It is therefore a generalisation which, as now an old man, I dare to make and it is based on meeting and learning about so many people in various circumstances. Some can remember amazing details, names and phone numbers, and others remember pictorially. I have met a few people with such amazing memories for names and texts that their brains must be like computers. Interestingly they have difficulty finding their way around in a new place; they lack a sense of direction. I first encountered this with a man whose brain had been damaged in a car crash. He had always spoken languages fluently and this memory function remained unimpaired. If he got out of a car and turned around, he did not know where the car was. Eventually he learned to memorise his movements so that he could work backwards to find the car which was standing behind him. Later I learned that he could drive a car and navigate but only with a route prepared in advance. If he deviated from the planned route he had to go back to where he made the mistake and take the right road. He could not cut across and pick up the road by following the direction. This puzzled me until I met another man renowned for knowing about thirty languages. He could learn a language in a few days and enjoyed the task. We agreed to meet and he arrived late at the venue. He had driven past it a few times before finding the place. To an examiner, he would have been top of the class. Outside college, he was almost disabled.

\section{Exams}

These observations lead to questions of intelligence, cleverness and education. Information can be pumped or sucked into a brain. What happens to that information is what matters for the benefit of the person and associates. Without a processing ability, information is useless. Exams test the ability to use acquired information but only in a limited way. Selection by exam results where memory predominates puts into the employed ranks a body of officials who rely on existing and proven facts and methods. They instinctively mistrust novelty.

There are people who combine memory skills with imagination and eventually, if they can control their frustrations, they will rise to the top ranks. Look at the military where promotion comes from below. A General will have been square bashing and boot polishing like all the other squaddies and moved up step by step according to exam successes. By avoiding speaking out of turn, they eventually achieve full control and it is only when confronted by the enemy in battle that their ability for original thought can be applied. Regardless of preparations with war games, all military planning is nothing until the first attack. Someone who can think on their feet has to be in control. Nothing in the selection process has prepared the leader for that day. An enemy that does not play by the rules can win. These days more fights are within borders than across them with attacks coming from strongly motivated "terrorists" who have no concern for ethics or the Geneva Convention. They did not gain control in an exam room.

\section{Doctors and Engineers}

The medical profession is selected from the early days in school. Many want to be a doctor to have a secure job and a more than adequate income with status. The perceived ability to save lives is power. Top students, those who score highly in exams, are offered the chance to enter medical school. In all cases, a good memory is essential. Many new vocabularies have to be learned. All the cures are from drugs so they have to learn what to administer and what side effects to avoid. Patient diagnosis and advice can be reduced to an online question and answer chart leading to prescribed drugs. The role of the general doctor is tightly controlled by bureaucracy. Like the military commanders, any doctors with fresh ideas must keep them to themselves until they get to the top of the ladder and even then, seek the support of peers.

Compare their predicament with engineers, a group often considered lower in status than doctors. Faced with a problem, an engineer will come up with at least six possible solutions and then analyse them to find the most practical answer. A doctor encountering the unknown will first search through the literature for the answer and if it 


\section{Ergonomics International Journal}

cannot be found will refer the patient to another doctor. The usual explanation is that failure by doctors can lead to death but in engineering it is only a machine that suffers. That is not true because often lives depend on the machine; think of aircraft. Of the two professionals, engineers use their problem-solving skills with pride. Watch two engineers in discussion over lunch. Sooner or later they will be sketching on the tablecloth. New ideas are the lifeblood of their careers; it excites them. Doctors live in fear. I once asked a doctor what his thoughts were when a patient enters his consulting room. I had heard that a good doctor can see what is wrong with a patient before the patient explains their problem. This is the oldfashioned view of doctors who often smelled the patient to know what was wrong. The doctor's reply surprised me.

"I wonder if this is the one that is going to sue me," he said. The job was not about helping the patient, it was to protect the doctor from the patient by only doing what the book says so that when cross questioned in court the doctor can claim to have only done what is officially approved. It was better to do nothing than do something of which he had no experience. If the patient dies and the doctor did nothing then the doctor did not kill the patient but if the doctor tried something and eventually the patient died then blame can be attached to the doctor. The heavily examined doctor had become a robot devoid of ethics.

Bank managers are the same. They are scared of their clients and their bosses. They have to lend to achieve targets but if they lend too much and the borrower cannot repay the manager are blamed. Their fear is compounded by the fact that their training to be a bank manger is of no help in any other type of job.

\section{Evaluation}

To know whether the right people are in the right jobs, it does not help to ask them if they are happy. There are too many attributes to mentality to reduce the compatibility of role and person to one aspect. People are flexible and pragmatic. They will accept a position to suit other circumstances such as a mother limiting her hours at work to allow more time with her children.

If the right mentalities are fitted to the right tasks, measuring output against targets may be a better way to assess the success of education, training, selection and placement. Even then, the targets may not be realistic. The police have to combine compassion, determination, aggression and empathy. Don't we all worry about the police? Ideally, they should all love me and be aggressive to everyone else. The world over, I see a common trait amongst police. A measure of civilisation would be how well the inclinations of the police are controlled. Unfortunately, we need these people.

Should the police be paid according to results? The highest pay goes to those in areas that are crime free. Similarly, doctors are paid according to the health of the people in their area. If no one is ill and the doctor has no work, those doctors get the highest pay because they are delivering what the public wants.

This approach is too simplistic. A doctor's influence on health is limited. A big part of the mix is food quality, water supply, sewage hygiene, exercise facilities and environmental pollution. Crime reduction is more than the police chasing crooks. Economic failings causing unemployment and geographical disasters such as earth quakes can cause social breakdown. Help beyond policing is needed to rebuild social cohesion. It is interesting to observe how charities have attracted perverts to work in areas needing help so that they can exploit the weak. Social groups have their home-grown networks and outside interference is often more disruptive than helpful. Gifts and food parcels are send to Romania every Christmas for the poor people. This greatly annoys the majority of Romanians who resent being thought of as incapable. Missionaries can cause social breakdown. A measure of their success would be how many have been recruited to their religious groups? Whether that is beneficial for the people as a whole is doubtful and these days there is resentment against invaders and empire builders.

Getting the role to suit the mentality is one of the most daunting challenges for governments today for this determines economic success and political satisfaction. There are two approaches: control and direction in an autocratic society and freedom of market forces under democracy. The former with strict dictators appears to be most efficient because no time is wasted moving from job to job and people will adjust and accept their placement. The democratic freedoms allow persistent wandering from post to post so that little gets done and the state has to support the unemployed and those between jobs. Both these claims are nonsense.

\section{Conclusion}

All employment has ultimately to provide a product or service to customers. Where that has been done by government control, it has been shown to fail to satisfy 


\section{Ergonomics International Journal}

end user needs. In other words, communism is a disaster. In a free economy, the controls apply to the incentives motivating the individual. Viewed from above, the academic in an ivory tower, the journalist condensing a complex situation to a five-minute broadcast, the searches for better jobs are difficult to comprehend. Looked at person by person, there is a process of shuffling into a well-fitting job that can be compared to trying on a suit or dress to see the effect. In practice, freedom in the labour market is efficient; the role fits the mentality. Ergonomics is the study of that process. 